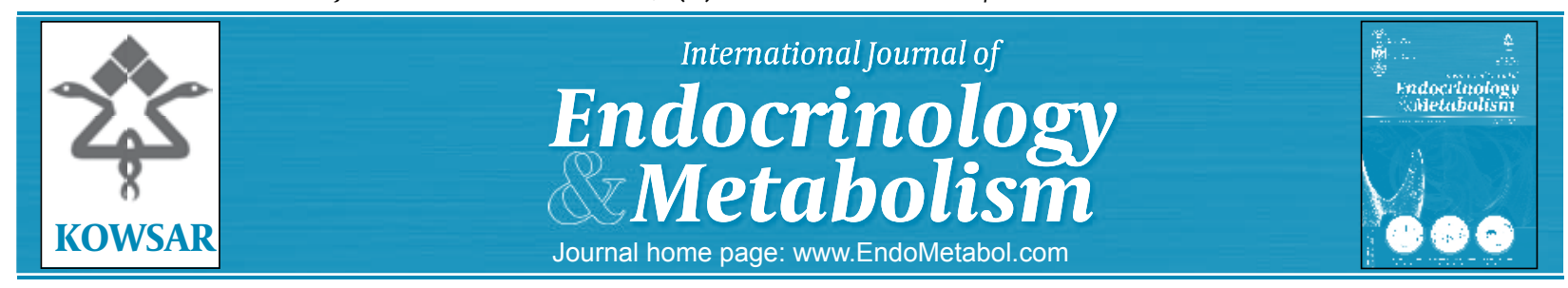

\title{
Tako-Tsubo Cardiomyopathy and Thyroid Dysfunction
}

\author{
Filippo M. Sarullo ${ }^{{ }^{*}}$, Antonino Di Franco ${ }^{2}$, Antonio Di Monaco ${ }^{2}$, Serena Magro ${ }^{1}$, Roberto \\ Nerla $^{2}$, Ylenia Salerno ${ }^{1}$, Giorgio Mandala ${ }^{1}$, Gaetano A. Lanza ${ }^{2}$ \\ ${ }^{1}$ Cardiac Rehabilitation Unit, Buccheri La Ferla Fatebenefratelli Hospital, Palermo, Italy \\ ${ }^{2}$ Division of Cardiology, Catholic University of Sacred Heart, Rome, Italy
}

\begin{tabular}{l}
\hline A R T I C L E I N F O \\
\hline Article type: \\
Mini Review Article \\
\hline Article history: \\
Received: 04 Jun 2011 \\
Revised: 07 Aug 2011 \\
Accepted: 20 Aug 2011 \\
\hline
\end{tabular}

Keywords:

Tako-Tsubo Cardiomyopathy

Thyroid Dysfunction

Ventricular Function

\begin{abstract}
A B S T R A C T
First described in a Japanese population in 1991, the Tako-Tsubo disease has recently been included among the primary acquired cardiomyopathies in the American Heart Association's disease classifications. Tako-Tsubo cardiomyopathy (TTC) is a reversible, often misdiagnosed condition, as it can easily mimic acute coronary syndrome. It has indeed been estimated that TTC can represent 1 to $2 \%$ of patients who present with suspected acute coronary syndrome. The disease is especially common in women. In its typical presentation, the identifying characteristic of TTC is the systolic bulging of the heart's apex with preserved contraction of basal myocardial segments. The acute left ventricular dysfunction, however, it is usually reversible, with contractile function usually recovering in a few weeks. The etiology of TTC is not completely clear. Many theories have been proposed, taking into account the role of hormone disturbances, acute toxic effects of catecholamines on cardiomyocytes, diffuse microvascular spasms, multivessel epicardial spasms, and acute myocarditis. Several researchers have suggested that TTC may occur as a rare complication of dysthyroidism. In particular, an acute hyperthyroid state has been proposed to be capable of triggering TTC, independently of its causes. Indeed, several cases of TTC associated with Graves' disease, Hashimoto thyroiditis, or excess levothyroxine therapy have been reported in the medical literature. The mechanism by which dysthyroidism can trigger TTC, however, remains poorly understood. In this review we investigated the role of thyroid dysfunction as a possible trigger for TTC.
\end{abstract}

Copyright $\odot 2011$ Kowsar M. P. Co. All rights reserved.

Implication for health policy/practice/research/medical education:

This work provides important information about the correlation between Tako-Tsubo Cardiomyopathy (TTC) and Thyroid dysfunction (TD). The article gives evidence to how doctors may have to refer to when confronted with a patients with such condiction as thyroid dysfunction and TTC, and the diverse methods that can be used to treat these conditions (TTC with TD).

Please cite this paper as:

Sarullo FM, Di Franco A, Di Monaco A, Magro S, Nerla R, Salerno Y, et al. Tako-Tsubo Cardiomyopathy and Thyroid Dysfunction. Int J Endocrinol Metab. 2011;9(4):369-72. DOI: 10.5812/Kowsar.1726913X.3386

\section{Tako-Tsubo Disease}

First described in the Japanese population in 1991 (1), Tako-Tsubo disease has recently been included among the primary acquired cardiomyopathies in the American Heart Association's disease classifications (2).

In its typical presentation, the identifying characteristic

* Corresponding author: Filippo Maria Sarullo, Cardiac Rehabilitation Unit , Buccheri La Ferla Fatebenefratelli Hospital, Via Salvatore Puglisi n.15, 90143 Palermo, Italy. Tel: +39-091479263, Fax: +39-091342336, E-mail: fsarullo@neomedia.it

DOI:10.5812/Kowsar.1726913X.3386

Copyright @2011 Kowsar M.P.Co. All rights reserved. of Tako-Tsubo cardiomyopathy (TTC; also variably known as apical ballooning syndrome, stress cardiomyopathy, broken heart syndrome, and ampulla cardiomyopathy) is the systolic bulging of the heart's apex with a preserved contraction of basal myocardial segments, so that, in systole, the left ventricle forms a shape similar to a tako-tsubo, the pot used by Japanese fishermen to catch octopus (1). TTC is a reversible, often misdiagnosed condition, as it can easily mimic acute coronary syndrome. It has been estimated that TTC can represent 1 to $2 \%$ of patients who present with suspected acute coronary syndrome (3). The condition is especially prevalent in women, and postmenopausal women have been reported to make up over $90 \%$ of the cases in most study samples (4-6). The most common symptom is 
chest pain, variably accompanied by diaphoresis, dyspnea, palpitations, nausea, or syncope. In some patients the clinical presentation can be dramatic, including acute heart failure or cardiogenic shock, due to the severe impairment of left ventricular function. The acute left ventricular dysfunction, however, is usually reversible, with contractile function usually recovering in a few weeks $(5,6)$. The condition is associated with a preceding stressful event in about twothirds of cases. Both emotional (e.g., death of a family member, financial disaster, severe argument) and physical (e.g., sepsis, cerebrovascular accidents, cocaine use, severe pain, trauma, surgical interventions) stressors can act as triggers, although TTC can occasionally occur in the absence of any precipitating event $(7,8)$.

The etiology of TTC is not completely clear. Many theories have been proposed, taking into account the role of hormone disturbances, acute toxic effects of catecholamines on cardiomyocytes, diffuse microvascular spasms, multivessel epicardial spasms, and acute myocarditis. The frequent association with stressful events suggests that an acute activation of the adrenergic system plays a crucial role in the pathogenesis of TTC. Notably, this is also supported by evidence that the peculiar contractile impairment of the middistal and apical segments of the left ventricle in TTC patients seems to parallel the regional density of cardiac adrenergic receptors (ARs). For instance, in a study with canine subjects, Mori et al.(9) found that $\beta$-ARs present a higher expression in the apical region of the heart, with a progressive decrease from apex to base. Accordingly, the apical and distal regions of the heart will be more subject to the negative effects of high catecholamine levels or sympathetic outflow, compared to the midbasal segments. Moreover, findings from Lyon et al. (10) suggest that the differences in ARs throughout the heart might mainly concern B2-ARs, which, when stimulated by high concentrations of circulating epinephrine (as achieved during strong stress stimuli), can result in a paradoxical negative inotropic effect due to a switch in intracellular signals in the cardiomyocytes from the $G_{s}$ to the $G_{i}$ protein. This intriguing hypothesis, however, needs to be confirmed in further studies.

Acute and exaggerated sympathetic activation (11) can result in cardiac dysfunction through a direct toxic effect on cardiomyocytes (i.e., adrenergic cardiomyopathy), similar to that observed in other hyperadrenergic states, such as pheochromocytoma (12) and subarachnoid hemorrhage (13). Accordingly, histologic abnormalities compatible with adrenergic cardiomyopathy, mainly consisting of a focal necrosis with hypercontrated myocardial fibers, have been reported in some patients with TTC (14).

Nonetheless, elevated levels of catecholamines can also trigger TTC by inducing severe coronary artery constriction, either in the epicardial vessels (15) or in the coronary microcirculation (16). A severe, transient coronary microvascular constriction has been hypothesized by several authors (17-19), and the evidence suggests that coronary flow reserve is impaired in the acute phase of TTC but improves at short-term follow-up along with left ventricular function (20). At present, however, definitive evidence of a major pathogenic role for coronary microcirculatory abnormalities in TTC is lacking because it is possible that the impairment in microvascular function is just an epiphenomenon of the disease rather than a primary cause of the disease.

\section{Thyroid and Tako-Tsubo Cardiomyopa- thy}

Several authors have suggested that TTC may occur as a rare complication of dysthyroidism. In particular, an acute hyperthyroid state has been proposed to be capable of triggering TTC, independently of its causes. Indeed, several cases of TTC associated with Graves' disease (21-24), Hashimoto thyroiditis (25), or excess levothyroxine therapy (26) have been reported in the medical literature (Table 1). The mechanisms by which hyperthyroidism (HT) trigger TTC, however, remain poorly understood (Figure 1).

A rapid increase of thyroid hormones might result in an acute activation of the adrenergic system, which, as dis-

\begin{tabular}{lll}
\hline \multicolumn{3}{l}{ Table 1. Cases of TTC Associated with HT } \\
\hline Cases of TTC Associated With HT & Pts with TTC & Mean Age, $\mathbf{y}$ \\
\hline Miyazaki S et al. (21) & 1 & 79 \\
Bilan A et al.(22) & 1 & 59 \\
Rossor AM et al.(23) & 1 & 61 \\
Sarullo FM et al. (24) & 1 & 55 \\
Sakaki T et al.(25) & 1 & 74 \\
Gowda RM et al.(26) & 1 & 69 \\
\hline
\end{tabular}

cussed above, plays a major role in the pathogenesis of TTC and might therefore be the effector of HT-triggered TTC. Nevertheless, there is conflicting evidence from the medical literature regarding the interrelationship between the thyroid and the adrenergic axis. Some studies have indeed shown that, in HT plasma, catecholamine levels are usually normal or less than normal (27). Other studies, however, have suggested that thyroid hormones can exaggerate the response to normal levels of catecholamines (28). Accordingly, many authors have shown that variations in thyroid hormone levels can alter the transcription of $\beta$ adrenergic receptors, ultimately favoring the inotropic and chronotropic stimulation of the heart (29). Thyroid hormones, on the other hand, exert direct negative effects on the cardiovascular system that might be responsible for TTC. These hormones are indeed known to alter heart rate, cardiac output, and systemic vascular resistance. Furthermore, in addition to increasing peripheral oxygen consumption and substrate requirements, resulting in a secondary increase in cardiac contractility, triiodothyronine, the active form of thyroid hormones, can directly increase cardiac inotropism $(30,31)$. After entering the myocardial cell by means of specific transport proteins in the cell membrane, triiodothyronine acts at the nuclear level by leading to tran- 


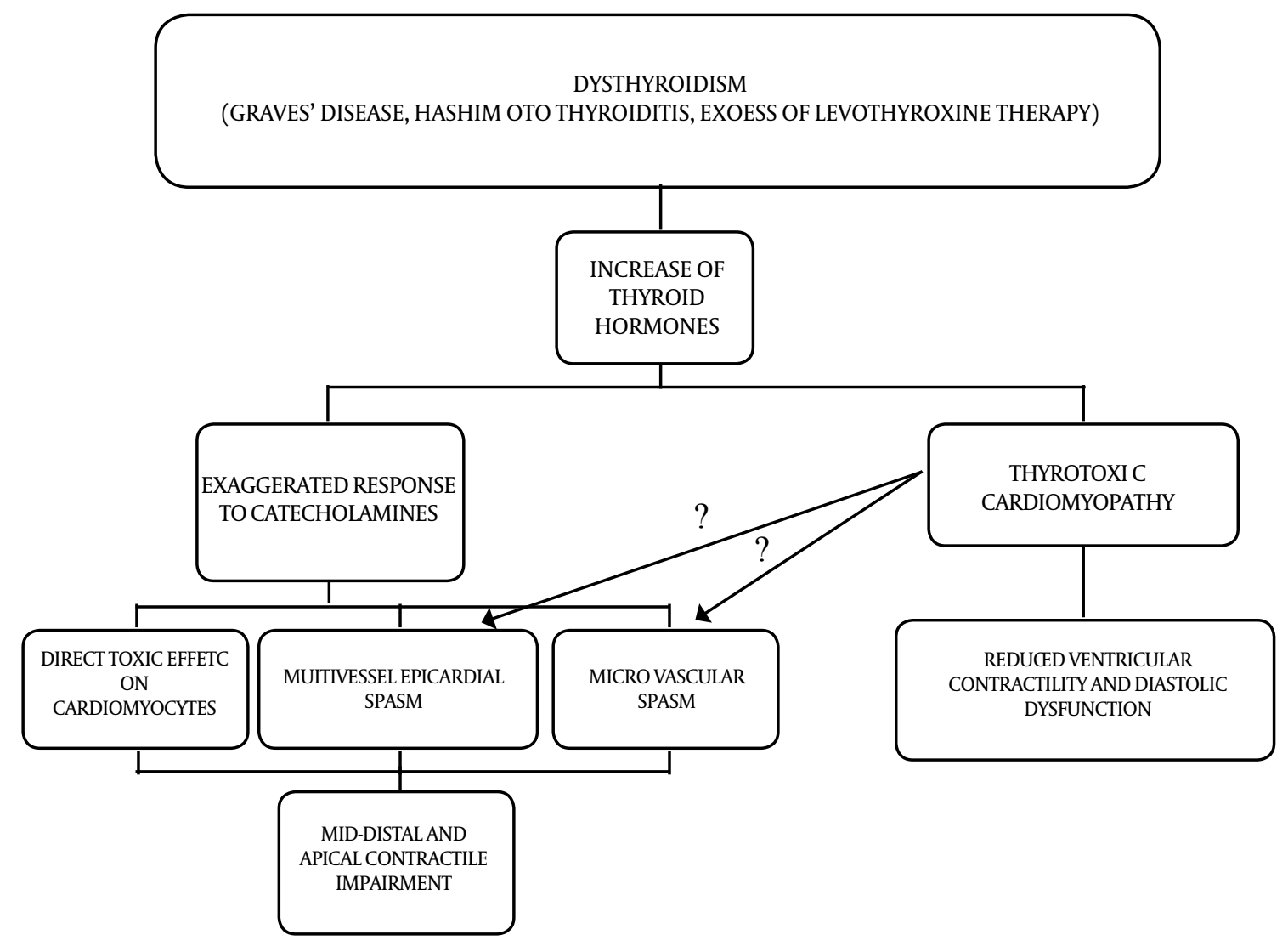

Figure 1. Proposed Mechanisms of Association Between Thyroid Dysfunction and Tako-Tsubo Cardiomyopathy (See Text)

scriptional activation of both the structural and regulatory cardiac proteins, such as $\beta 1$-adrenergic receptors (ARs), $\alpha$ -myosin heavy chain, $\mathrm{Na}^{+} / \mathrm{K}^{+}$ATPase, voltage-gated potassium channels, sarcoplasmic reticulum $\mathrm{Ca}^{++}$-ATPase, and phospholamban, which are all involved in the regulation of both systolic and diastolic function (32).

An excess of thyroid hormones, however, has been shown to possibly result in dramatic impairment of left ventricular function (33). The underlying pathophysiology of this "thyrotoxic cardiomyopathy" remains unclear. In many cases it has been attributed to a tachyarrhythmia-related depression of the heart (tachyarrhythmia-mediated cardiomyopathy) leading to an increased level of cytosolic calcium during diastole with reduced ventricular contractility and diastolic dysfunction (34). In a small subset of patients with persistent sinus tachycardia or atrial fibrillation, low-output heart failure (thyrotoxic cardiomyopathy) can develop, although this is reversible when a euthyroid state is reestablished $(25,31,35,36)$.

Still, TTC in HT patients might be triggered by multivessel epicardial artery spasms, which early studies suggested to play a pathogenic role in some patients (1). Several studies have indeed suggested that vasospastic angina may be induced in patients with both transient or persistent HT. Featherstone and Stewart (37) also reported a patient with hyperthyroid Graves' disease who had vasospastic angina. They demonstrated that, in a hypothyroid state, the patient became free of angina after iodine 131 therapy, whereas the patient's angina returned in the hyperthyroid stage by increasing levothyroxine sodium. Moliterno and colleagues (38) reported a case in which the repeated occurrence of episodes of myocardial ischemia due to coronary spasms was correlated with repeated transient elevations in thyroid hormone levels. Vasospasm was also angiographically identified in a patient with occult HT by Wei et al. (39). Severe reversible ischemia due to excess thyroid administration has also been reported (40). Finally, in a recent study, Cakir (41) suggested that TTC might not be related to thyrotoxicosis per se, but might be a complication of the autoimmunity of thyroid disease, which is a new perspective of the puzzle. Again, more studies are needed to confirm this idea.

In conclusion, the question of whether elevated thyroid hormones levels can precipitate TTC is still debatable and requires further research. Nevertheless, it is advisable that physicians look for a treatable underlying condition in TTC patients because this requires a different treatment plan. In this sense, a diagnosis of HT, although rare, should be considered.

\section{Acknowledgments}

We thank Edna Sabina Salguero for assisting with the English translation. 


\section{Financial Disclosure}

None declared.

\section{Funding/Support}

None declared.

\section{Refetrences}

1. Dote K, Sato H, Tateishi H, Uchida T, Ishihara M. [Myocardial stunning due to simultaneous multivessel coronary spasms: a review of 5 cases]. J Cardiol.1991;21(2):203-14.

2. Maron BJ, Towbin JA, Thiene G, Antzelevitch C, Corrado D, Arnett D, et al. Contemporary Definitions and Classification of the Cardiomyopathies. Circulation. 2006;113(14):1807-16.

3. Kawai S, Suzuki H, Yamaguchi H, Tanaka K, Sawada H, Aizawa T, et al. Ampulla cardiomyopathy ('Takotusbo' cardiomyopathy)-reversible left ventricular dysfunction: with ST segment elevation.Jpn Circ J. 2000;64(2):156-9.

4. DesmetWJ, Adriaenssens BF, Dens JA. Apical ballooning of the left ventricle: first series in white patients. Heart. 2003;89(9):1027-31.

5. Sharkey SW, Lesser JR, Zenovich AG, Maron MS, Lindberg J, Longe TF, et al. Acute and Reversible Cardiomyopathy Provoked by Stress in Women From the United States. Circulation. 2005;111(4):472-9.

6. Tsuchihashi K, Ueshima K, Uchida T, Oh-mura N, Kimura K, Owa $\mathrm{M}$, et al. Transient left ventricular apical ballooning without coronary artery stenosis: a novel heart syndrome mimicking acute myocardial infarction. Angina Pectoris-Myocardial Infarction Investigations in Japan. J Am Coll Cardiol. 2001;38(1):11-8.

7. Gianni M, Dentali F, Grandi AM, Sumner G, Hiralal R, Lonn E. Apical ballooning syndrome or takotsubo cardiomyopathy: a systematic review. Eur Heart J. 2006;27(13):1523-9.

8. Sharkey SW, Windenburg DC, Lesser JR, Maron MS, Hauser RG Lesser JN, et al. Natural history and expansive clinical profile of stress (tako-tsubo) cardiomyopathy. J Am Coll Cardiol. 2010;55(4):333-41.

9. Mori H, Ishikawa S, Kojima S, Hayashi J, Watanabe Y, Hoffman JI et al. Increased responsiveness of left ventricular apical myocardium to adrenergic stimuli. Cardiovasc Res.1993;27(2):192-8.

10. Lyon AR, Rees PS, Prasad S, Poole-Wilson PA, Harding SE. Stress (Takotsubo) cardiomyopathy-a novel pathophysiological hypothesis to explain catecholamine-induced acute myocardial stunning. Nat Clin Pract Cardiovasc Med. 2008;5(1):22-9.

11. Lavi S, Nevo O, Thaler I, Rosenfeld R, Dayan L, Hirshoren N, et al. Effect of aging on the cardiovascular regulatory systems in healthy women. Am J Physiol Regul Integr Comp Physiol. 2007;292(2):R788-93.

12. Otsuka M, Kohno K, Itoh A. Periodic fluctuation of blood pressure and transient left ventricular apical ballooning in pheochromocytoma. Heart. 2006;92(12):1837.

13. Naredi S, Lambert G, Eden E, Zall S, Runnerstam M, Rydenhag B, et al. Increased sympathetic nervous activity in patients with nontraumatic subarachnoid hemorrhage. Stroke. 2000;31(4):901-6.

14. Wittstein IS, Thiemann DR, Lima JAC, Baughman KL, Schulman SP, Gerstenblith G, et al. Neurohumoral Features of Myocardial Stunning Due to Sudden Emotional Stress. New Engl J Med. 2005;352(6):539-48.

15. Adameova A, Abdellatif Y, Dhalla NS. Role of the excessive amounts of circulating catecholamines and glucocorticoids in stress-induced heart disease. Can J Physiol Pharmacol. 2009;87(7):493-514

16. Lanza GA, Crea F. Primary coronary microvascular dysfunction: clinical presentation, pathophysiology, and management. Circulation. 2010;121(21):2317-25.

17. Bybee KA, Prasad A, Barsness GW, Lerman A, Jaffe AS, Murphy JG, et al. Clinical characteristics and thrombolysis in myocardial infarction frame counts in women with transient left ventricular apical ballooning syndrome. Am J Cardiol. 2004;94(3):343-6.
18. Elesber A, Lerman A, Bybee KA, Murphy JG, Barsness G, Singh M et al. Myocardial perfusion in apical ballooning syndrome correlate of myocardial injury. Am Heart J. 2006;152(3):469 e9-13.

9. Fazio G, Sarullo FM, Novo G, Evola S, Lunetta M, Barbaro G, et al. Tako-tsubo cardiomyopathy and microcirculation. J Clin Monit Comput. 2010;24(2):101-5.

20. Galiuto L, De Caterina AR, Porfidia A, Paraggio L, Barchetta S, Locorotondo G, et al. Reversible coronary microvascular dysfunction: a common pathogenetic mechanism in Apical Ballooning or Tako-Tsubo Syndrome. Eur Heart J. 2010;31(11):1319-27.

21. Bilan A, Ignatowicz A, Mosiewicz J, Wysokinski A. Dyspnea as a dominant clinical manifestation in a patient with takotsubo cardiomyopathy treated for chronic obstructive pulmonary disease and hyperthyroidism. Pol Arch Med Wewn. 2009;119(4):265-

22. Miyazaki S, Kamiishi T, Hosokawa N, Komura M, Konagai H, Sagai $\mathrm{H}$, et al. Reversible left ventricular dysfunction "takotsubo" cardiomyopathy associated with hyperthyroidism. Ipn Heart J. 2004;45(5):889-94.

23. Rossor AM, Pearce SH, Adams PC. Left ventricular apical ballooning (takotsubo cardiomyopathy) in thyrotoxicosis. Thyroid. 2007;17(2):181-2.

24. Sarullo FM, Americo L, Accardo S, Cicero S, Schicchi R, Schiro M, et al. Tako-tsubo cardiomyopathy observed in a patient with sepsis and transient hyperthyroidism. Monaldi Arch Chest Dis. 2009;72(1):33-6.

25. Sakaki T, Fujioka Y, Akagami T, Masai M, Shimizu H, Sakoda T, et al. Cardiac wall motion abnormalities observed in a patient with transient hyperthyroidism.Jpn Heart J. 2004;45(6):1071-7.

26. Gowda RM, Khan IA, Soodini G, Vasavada BC, Sacchi TJ. Acute myocardial infarction with normal coronary arteries associated with iatrogenic hyperthyroidism. Int J Cardiol. 2003;90(2-3):327-9.

27. Polikar R, Burger AG, Scherrer U, Nicod P. The thyroid and the heart. Circulation.1993;87(5):1435-41.

28. Gerald S L. Catecholamine sensitivity, thyroid hormone and the heart: A reevaluation. Am J Med.1971;50(4):413-20.

29. Walker JD, Crawford FA, Kato S, Spinale FG. The novel effects of 3,5,3'-triiodo-L-thyronine on myocyte contractile function and beta-adrenergic responsiveness in dilated cardiomyopathy. $J$ Thorac Cardiovasc Surg. 1994;108(4):672-9.

30. Dillmann WH. Biochemical basis of thyroid hormone action in the heart. Am J Med.1990;88(6):626-30.

31. Klein I. Thyroid hormone and the cardiovascular system. Am J Med.1990;88(6):631-7.

32. Klein I, Ojamaa K. Thyroid hormone and the cardiovascular system. N Engl J Med. 2001;344(7):501-9.

33. Pereira N, Parisi A, Dec GW, Choo J, Hajjar R, Gordon PC. Myocardial stunning in hyperthyroidism. Clin Cardiol. 2000;23(4):298300.

34. Dahl P, Danzi S, Klein I. Thyrotoxic cardiac disease. Curr Heart Fail Rep. 2008;5(3):170-6.

35. Fadel BM, Ellahham S, Ringel MD, Lindsay J, Jr., Wartofsky L, Burman KD. Hyperthyroid heart disease. Clin Cardiol. 2000;23(6):402-8

36. Kantharia BK, Richards HB, Battaglia J. Reversible dilated cardiomyopathy: an unusual case of thyrotoxicosis. Am Heart J. 1995;129(5):1030-2.

37. Featherstone HJ, Stewart DK. Angina in thyrotoxicosis. Thyroidrelated coronary artery spasm. Arch Intern Med.1983;143(3):554-5.

38. Moliterno D, DeBold CR, Robertson RM. Case report: coronary vasospasm--relation to the hyperthyroid state. Am J Med Sci. 1992;304(1):38-42.

39. Wei JY, Genecin A, Greene HL, Achuff SC. Coronary spasm with ventricular fibrillation during thyrotoxicosis: response to attaining euthyroid state. Am J Cardiol. 1979;43(2):335-9.

40. Bergeron GA, Goldsmith R, Schiller NB. Myocardial infarction, severe reversible ischemia, and shock following excess thyroid administration in a woman with normal coronary arteries. Arch Intern Med.1988;148(6):1450-3.

41. Cakir M. Takotsubo cardiomyopathy in thyrotoxicosis. Int J Cardiol. 2010;145(3):499-500. 